Available online at www.refaad.com

BAES, 3(2)2019, 70-78

Research Article

Bulletin of Advanced English Studies (BAES)

Journal Homepage: https://www.refaad.com/views/BAES/home.aspx

ISSN: 2617-6459 (Online) 2617-6440 (Print)

\title{
The Role of Input in Second Language Acquisition: An Overview of Four Theories
}

\author{
Nesreen Saud Alahmadi a* \\ ${ }^{a}$ Faculty of Art and Humanities, English Language Centre, Taibha University, Saudi Arabia
}

\begin{abstract}
Various theories of second language acquisition (SLA) attribute significant importance to the role of input in second language (L2) learning. The current paper attempts to explore the role of input through an overview of four theories of SLA. These theories highlight different views on the value of second language input to learners' linguistic abilities. These theories are: the Input Hypothesis (Ellis, 1994, Krashen, 1985, 1989, Doughty \& Long, 2003; Mackey \& Gass 2015), the Input-Interaction-Output Hypothesis (Gass, 1988, 1991, 1994, 1997), the Input and Interaction Hypothesis (Long, 1980, 1985, Brown, 2007, Long, 2016) and the Autonomous Induction Theory (Carroll, 1999, 2001, 2007, Loewen \& Sato 2017). Also, the role of interaction for L2 input will be discussed. In fact, learners' acquisition of L2 depends on different factors, either external or internal as well as on learners' experience of the language. Therefore, accounts of successful SLA have emphasised the influence of the quality of the input provided to learners, as it counts as one of these external factors. However, input alone cannot facilitate L2 learning, as learners cannot develop full linguistic ability in the target language without processing and practicing the transmitted information through interaction. The present paper is a brief review of the significant role of language input in SLA. Accordingly, the role of input is discussed the perspective of different theories of language learning.
\end{abstract}

Keywords: Comprehensible Input; Language Input; Language intake; L2 Learning; Second Language Acquisition.

\section{Introduction}

As a concept, the importance of input has been extensively acknowledged in the field of second language acquisition (SLA). According to Long (1996,2017), input is considered to be one of the most significant components of the process of SLA. As Gass (1997) states, input is considered the primary source of data to second language (L2) learning and learning cannot simply occur without input, for learners, input is the only source available to construct their language competence. Researchers in the field regardless of the theoretical approach have generally supported this statement. The input received by the L2 learners may be oral or written, which may or may not always be 'comprehensible' (Krashen, 1985), 'comprehended' (Gass, 1997), 'modified' or 'pushed' or 'negotiated through 'negotiation for meaning'. Therefore, the role of input in SLA will be discussed, outlining four theories of SLA, namely the Input Hypothesis (Krashen, 1985,1989), the Input-Interaction-Output Hypothesis (Gass, 1988, 1991, 1994, 1997), the Input and Interaction Hypothesis (Long, 1980, 1985) and the Autonomous Induction Theory (Carroll, 1999, 2001, 2007). This paper aims to explore how each theory impacts (theoretically and/or practically) upon SLA.

The importance of the language input in SLA is given great emphasis in the literature, which indicates that many studies in this area of research have been conducted to investigate the important role and processing of linguistic input. From this plethora of research, it can be summarised that SLA simply cannot take place without

\footnotetext{
${ }^{*}$ Corresponding author

Email address: Nesreen.s.uni@hotmail.com (Nesreen Saud Alahmadi)

DOI: https://doi.org/10.31559/baes2019.3.2.1

Received Date: 13/10/2019

Accepted Date: 30/11/2019
} 
exposing the learners to the target language through input (Gass, 1997, Mackey \& Gass 2015). For example, (VanPatten \& Williams, 2007, Patten and Benati, 2010, Shimanskaya, 2018) have highlighted that language input is significant for language learners to build their L2 competence as well as is considered to be a primary source of mental representation of the language. Therefore, the significance and the role of language input have been supported by a number of languages learning theories such as the behaviourist, mentalist, and interactionist theories, Ellis (2008). According to Bahrani (2013), the necessity of language input is conceded for learners' linguistic competence, although not all SLA theories attribute the same level of importance to the role played by input in the process of language acquisition. However, in many SLA theories, language input is considered to be an essential factor for learning, while in other theories it is given only a minimal role. In fact, what has been argued by some researcher such as (McLaughlin, 1987, Zhang, 2009, and Carroll, 2007, Ellis, 2019), concerning the role of input in language learning from the perspective of many language-learning theories is the conceptualisation of how language learners processes linguistic information through input. (Doughty \& Long, 2003)

However, as mentioned earlier, language input is defined as the major source of linguistic data to which a learner is exposed (Long, 1982). According to Ellis (1994), in order for SLA to occur, there are two prerequisites: 'L2 input that is obtainable to the learners and a set of internal mechanisms to account for how L2 linguistic features are processed' (p.14). Therefore, this paper aims to discuss the role of input from the perspective of various theories on language learning, as some overlapping theories argue about the role between interaction and input (Krashen, 1985; Gass, 1997). Nevertheless, there are many other factors that impact upon SLA and influence the role of input, which are also investigated. These include, for example, biological factors, cognitive factors, social factors and environmental factors. This paper will give an overview of the role of input in SLA. Four theories of SLA will be presented as a means for focusing attention on the role of input and output on SLA. The role of input will be discussed and summarised within each model of SLA.

\section{The Input and Interaction Hypothesis}

According to Long (1996,2016,2017), SLA theories need not to account for all the facts in every description to be workable. Long (1996) asserts that theories of SLA seldom address every aspect of the topic. Therefore, theories do vary in scope. Long (1980) stated that in order to understand the process of L2 learners' internal grammar, the role of comprehensible input must be recognised by any theory of SLA. In addition, according to Krashen's hypothesis (2009) of acquisition through comprehensible input as cited in Akan (2018), "Acquisition requires meaningful interaction in the target language - natural communication - in which speakers are concerned not with the form of their utterances but with the messages they are conveying and understanding."(p.120). Thus, due to the important role of comprehensible input in SLA, it can be comprehended as sets of processes in acquisition. According to Fang (2010), the first set of processes (I) is to turn input into intake. This is generally referred to as 'input processing'. The learner thus receives knowledge from input but still must develop an acquired system, as not all the information from intake is automatically converted into the acquired system. The second set of processes (II) includes those linguistic features that stimulate the knowledge of intake and restructure the development of the learner's linguistic system (Fang, 2010). The third set of processes (III) consists of certain aspects of language production, for instance, the monitoring, accessing and controlling of knowledge. Accordingly, input processing involves the first set of processes, which basically focuses on turning language input into intake. Although input processing can be examined from various perspectives, the notion of form-meaning connections is used to discuss the processes involved in the conversion of input to intake (Sun,2008).

As a matter of fact, Long's (1980) argument of the importance of comprehensible input was as follows: First, there is a need to prove that comprehension promotes acquisition, and second, more investigation needs to be conducted to prove that conversational modifications in 'language input' will probably lead to better comprehension. From this, according to Long's (1980) claim, we will be able to determine whether 'conversational modifications' promote acquisition. However, the influence of interaction will remain controversial in the field of SLA despite the encouraging findings of Long's research. Long (1996) claimed that in many learning situations, comprehensible input was not always necessary nor sufficient to promote the acquisition process. Therefore, a learner's L2 competence can not only rely on interactional modifications cannot be the only this mechanism to be developed. Accordingly, it became increasingly evident that linguists would need to search for further interactional processes that could support learners access to an L2; this can be achieved not only through language forms that are generated in the comprehensible input but also, interaction through conversation (Gass,1998).

Moreover, Long (1996), in his updated version of the Interaction Hypothesis, points out that 'negotiation for meaning, and especially negotiation work that triggers interaction adjustments by the NS or more competent interlocutor, facilitates acquisition because it connects input, internal learner capacities, particularly selective attention, and output in productive ways' (p. 451, 452). Therefore, through negotiation, according to Fang (2010), a learner's additional resources of learning may be placed to: (a) a particular link between what experience do the learners have about the L2 and what the L2 really is; and (b) the limited knowledge of a particular area of in L2 in which the learner has no previous knowledge or limited information. Here, interaction can be described according to Fang (2010), as an 'attention-drawing device', which means the role of interaction is to draw the learner's 
attention to the unknown features of a language. In other words, the acquisition of certain elements of a language may take place during interaction.

\section{Krashen's Input Hypothesis}

In the early 1980s, the American linguist Stephen Krashen $(1985,1989)$ explained that language cannot be learnt through endless repetition, but, on the contrary, it can be learnt as the result of interior factors, such as the mental processing of linguistic features based on the input that learners received. Krashen (1989) asserted that input should be as thorough as possible in order for language learning to occur. In his input hypothesis, he claimed that the language that we acquire subconsciously, especially when it is received in an anxiety-free environment, could be effortlessly used in spontaneous conversation due to the availability of linguistic elements to L2 learners.

Krashen $(1985,1989)$ also claimed that the successful acquisition of an L2 depends on the nature of language that L2 learners received. For instance, for learners to acquire a language, it needs to be comprehensible even if it is vaguely above their production level. He called this comprehensible input, which he defines as the information that learners already know plus the next level up, and the learners have to be exposed to the L2 in a relaxed setting when their affective filter was lowered. As Krashen stated,

The best methods of language learning are therefore those that supply 'comprehensible input' in low anxiety situations, containing messages that students really want to hear. These methods do not force early production in the second language, but allow students to produce when they are 'ready', recognizing that improvement comes from supplying communicative and comprehensible input, and not from forcing and correcting production. (1989, p.22)

This input; however is roughly tuned in order to deliver less language instructions in any L2 input, where only specific language features are selected for conscious-explicit-learning. Therefore, roughly tuned input assists SLA. As Krashen (1985) also argued, highly tuned input when combined with conscious learning does not necessarily increase L2 learners' competence.

Krashen's 'Input Hypothesis' claims that learners acquire language by one way only that based on; understanding the messages they receive or by exposure to a comprehensible language input. This model emphasises that in order for acquisition to take place there must be a period of time that allows learners to process input without any pressure to produce output (Krashen, 1985). However, this model shed lights on the idea that the 'affective filter' must also be 'low enough to allow the input "in"' (Bahrani, 2013, p.22). Furthermore, Krashen's model also places great importance on different forms of language aspects to function as comprehensible input.

In addition to Krashen's suggestions concerning the effectiveness of input, he states that 'insufficient quantity of input' or 'inappropriate quality of input' both count as possible causes of fossilisation (1985,p.44). Hence, one can conclude from Krashen's model of SLA that input should not be repetitive in nature in order to facilitate SLA (1985). In summary, Krashen's theory of SLA claims that constant access and regular exposure to language input should facilitate SLA only when it is comprehended by the L2 learners with a low affective filter, which might have been modified in one way or another to the learners' level or above, as well as rich in various language forms.

However, the Input Hypothesis firmly claims that SLA can only occur when language learners are exposed to certain L2 features that they can fully comprehend. Krashen (1990) associated comprehensible language input as being both contributory and variable in SLA. According to Krashen(1990), SLA can take place, when L2 learners are exposed to a kind of comprehensible language input that contains linguistic forms that are higher than their language competence.

\section{Critiques of the Input Hypothesis}

Nevertheless, the Input Hypothesis was criticised strenuously in the field of SLA, despite the major impact it has on emphasising the significant role of input in L2 learning. In fact, various researches challenge the effectiveness of Krashen's hypothesis by providing plentiful evidence indicating that exposure to comprehensible input on its own is always sufficient for L2 learning (McLaughlin, 1987. Liu, 2015). Indeed, the type of implicit language learning in 'input' does not always work with L2 acquisition as the learners have already developed a language system, which is difficult to change in the later stages of life, unlike the acquisition of one's first language, which has been learnt and acquired since childhood. That means L2 acquisitions require more than an input to be abundantly mastered.

Also, researchers argue with Krashen's theory that 'processing of comprehension is different from processing of production. And the ability to understand meaning conveyed by sentences differs from the ability to use a linguistic system to express meaning' (Zhang, 2009, p.92). However, McLaughlin (1987) expresses major concerns in regard to the effectiveness of the input hypothesis. He claims that it is not an easy task to identify the 'concept of a learner's level'. In fact, other factors such as individual differences should also be considered, as the application of rules in any language classroom will be limited due to these differences. In other words, determining the accurate level of every L2 language learner and providing the right input accordingly is a challenging task to fulfil, if not impossible.

As a result, some issues should be taken into consideration and with caution in regard to many other factors, 
such as individual differences, before we fully apply Krashen's theory of language comprehensible input to SLA. Indeed, in spite of the significance of input gained by researchers in the field of SLA, the evidence of the effectiveness of Krashen's hypothesis of comprehensible input falls short of identifying the quantity and quality of input that should be provided to L2 learners in order for language acquisition to take place. Thus, comprehensible input is of course, necessary for learners when it is included in line with other learning factors that affect learners' language competence.

\section{The Input-Interaction-Output Model (Gass, 1997)}

Another model that addresses the role of comprehensible input, in addition to the hypothesis of Krashen, is the Input-Interaction-Output model. As proposed by Gass (1997, Mackey\& Gass 2015, VanPatten, 2017), in this model, learners receive language as input that supported by interaction; they manipulate and produce as output, thus establishing the basis to acquire a second language. As a matter of fact, Krashen's comprehensible input hypothesis, which he proposed in 1981 cited in Bahrani (2013), asserts that SLA takes place simply by different means of comprehensible input, which are revived by the language learners. In other words, L2 input can be described as practical and effective if it is only beyond the learners' language competence.

Gass (1997) supports this hypothesis and asserts that language input is significant for learners but only when it takes into consideration both the internal and external factors that facilitate language acquisition. For example, L2 learners must receive enough exposure to the input to be able to 'formulate a conceptual representation' (Sun, 2008, p. 4). This can be done through certain linguistic forms that can be compared with the learner's current competence through an apperceived structure, such as the learner's existing knowledge, which helps them to acquire the target language. (Gass 1997, Mackey \& Gass 2015) also emphasise this aspect of the model, which is related to input and interaction, and identifies it as 'the information processing model' in which the learner's attention is drawn to the form of language to be learnt; only then are the unrecognised parts of linguistic forms provided through language construction in order not to overlap the learners' existing knowledge the L2.

Furthermore, Gass $(1991,1994,1997$,$) \& (Mackey \& Gass 2015) emphasised the role of input, which she$ considered to be significant not only for the comprehended input but the conception of a comprehensible input. According to Gass, what counts in the language input is the level of comprehension of that input, as it should be involved in the L2 learning process. As a result, language input has broader scope for SLA that cannot be contributed to the limitation of comprehensible input. The level of the effectiveness of language input depends on turning it into a comprehensible form. This can be achieved only when the learners process information from (intake) into (input). Indeed, L2 learners are exposed to different language inputs, which will not always be within their language competence. For example, some linguistic features are more noticed for some learners more than others, due to different factors such as previous experience and knowledge they have, the frequency of some features among others and the amount of attention learners have towards the new L2 features (Gass, 1997). Hence, in her theoretical model for SLA, Gass (1997) attributes the qualitative of language input not to its 'comprehension' but rather emphasises the learner's level of language proficiency.

In Gass's (1997) view, the Input-Interaction-Output Hypothesis is a major component of SLA. As she describes the acquisition process, first, 'the learner notices incoming data in line with individual affective, attitudinal and linguistic filters (apperception stage)'(McCarthy, 2014, p.8).In this stage, the learner starts to process and analyse the available data in the 'comprehended input' prior to the 'intake' stage of learning. In this stage, L2 learners start to formulate the hypotheses received about the L2. In fact, the 'intake' stage is defined, according to Gass (1997), as 'the vital stage between receiving information through input and forming grammar' (P. 44). Learners will then be able to bridge the gap between received and existing knowledge of the rules. This stage is called 'integration', where the linguistic rules of the target language are shaped and strengthened. This process, which leads the learners to move from 'input' to 'output', is crucial in this model. Consequently, learners are able to modify the information and linguistic features of L2 through input modification in the 'form of negotiation and native-speaker modification, that is, interaction' (Gass, 1997, p.34).

Nevertheless, in the stage of the 'negotiation of meaning', learners are involved in the learning process through the information provided in the input, and they may be able to request clarification for certain linguistic aspects using the target language. These requests modify their linguistic abilities to allow them to comprehend. This process, according to Gass (1997), is called 'learners receive modified input', and those learners then 'modify their output' until an adequate level of competence are reached (McCarthy, 2014, VanPatten, 2017). In fact, 'Implicit forms of feedback include negotiation strategies such as confirmation check, clarification requests, comprehension checks and recasts' (Gass, in Van Patten \&Williams, 2007: 182). However, this model of SLA emphasises the importance of interaction through a modified language input in order for learners to acquire the target L2, thereby strengthening their language competence.

\section{Carroll's Autonomous Induction Theory}

Another theory to be discussed relating to the role of input in SLA is Carroll's Autonomous Induction Theory (1999, 2001, 2007), and (Rezabeigi \&Shakouri, 2015). This theory outlines how the input is processed for parsing 
(linguistics analysis). According to Carroll (1999), it is necessary to provide integration through input to process linguistic features in SLA. Basically, this theory claims that linguistic faculty is comprised of a chain of representations, with the lowest level interacting with physical stimuli, and the highest with conceptual representations' (Carroll,1999 cited in Sun, 2008, p.6). In fact, Carroll (2007) argues that there are two different but related sub-theories to the rule of input in explaining the mechanism of SLA, as both of these sub-theories combine the rule of input. The first one is called (1) a 'processing theory, i.e., how input enters the system of learner's language such as the speech signal (bottom-up) or from the conceptual system (top-down)', and (2) a 'learning theory, i.e.,how novel information gets created to resolve learning problems'(Rezabeigi\&Shakouri, 2015, p. 2). Therefore, in order to constrain the nature of SLA, the processing and the learning theory should be taken into consideration. Also, Carroll (2001) provides a general approach to the 'representation of knowledge and by specifying the way in which linguistic information is processed by parsers' (Hulstijn, 2013, p. 12).

Furthermore, Carroll (1999, 2001, Maftoon, 2015) points out that a distinction between learning the language through processing information for acquisition and for parsing. In regard to the notion of comprehensible input, the acquisition mechanisms accrue when parsers fail to be triggered. This agrees somewhat with the notion of insufficient language input, where acquisition cannot take place (incomprehensible input). However, according to Carroll, it is somewhere difficult to notice the gap between the input provided for the learners and acquisition of the cognitive comparison of the process information. In other words, successful parsing occurs when representations are combined in any L2 features for each processor. Thus, failures in this process usually happen when the rules are not available in the input, being either missing or misplaced. Consequently, the rules nearest to effective parsing, for example, a 'particular unit' would be chosen in order for the process of the information to be checked and only then would the most incremental review be considered. However, the process of parsing should be continuedly repeated until acquisition takes place. Therefore, failing in acquiring the parsing could be attributed to the incomprehensible input.

However, Carroll $(1999,2001)$ stated that any attention to new linguistic features in the input should take into consideration the relation between the interaction of learners' attention and their existing and current knowledge of L2 rules. In her view of the role of input, attention is aroused after the learner has a base for processing linguistic features, which are processed preliminarily but at the same time is not a precondition for the production of the new rules. Yet within Carroll's (2001) processors of language input, there is also a mention of cognitive processing that is defined as the selections of certain functions that restrict the number of a learner's structures that undergo language analysis through input.

Furthermore, in regard whether the role of input is 'comprehensible or incomprehensible', Carroll (2000) opposes the theory of Gass (1997) that defines the mechanism of sequences input as a sequence of processing linguistic rules. On the contrary, Gass conceptualises intake as a result of detachment from the comprehended input. However, according to Carroll's view of input, comprehension input involves conscious reflection of cognitive processing of information in L2 that cannot be predicted as a result between intake and input. According to Jackendoff (2002), if any stage of intake follows a comprehended input, the mental comparison between the two can be opened for observation in terms of the conscious production of L2, although the unconscious process is difficult to trace and mark between input and intake.

However, in Carroll's theory of language input, intake and input cannot be considered as acquisition stimulation, but rather SLA input works as a mental construct. In fact, Carroll's theory provides distinctive insights into SLA and differentiates between the role of input and language stimulation. According to her theory, language stimulation is more important than input, which is considered to be an external factor of SLA. Thus, to Carroll, previous research on language input did not explain exactly how language stimulus becomes a language 'intake'. Hence, the nature of signal processing and linguistic parsing, from a conceptual viewpoint, needs to be accounted for in the field (Jackendof, 2002). From this perspective, a distinction and a reflection of the difference between 'input to language learning' and 'input to processing' will be needed to verify each of these input roles (Maftoon,2015).

However, the conceptual views of Carroll's theory of input are divided into three types of input that play an important role in SLA. According to Maftoon (2016), the first type of input is identified as 'Input-to-processing mechanisms', which are defined as the actual data provided in the input that work as stimuli for L2 learning. The second type of input is 'input to language learning mechanisms', which serve only the acquisition of the phonetic features of L2.According to Maftoon (2016), this is a 'phonetics processor which creates a structured prosodic representation as output using the speech signal as input. The resulting representation activates a lexical entry of the word in the mental lexicon. Then, the morphosyntactic processor uses the information in the activated lexical entry in the structure of the sentence' (p. 426). The third type of input is 'input to the Language Acquisition Device (LAD)', which is used to improve the system of L2 and gives further restructuring to the L2 learning process.

In other words, Carroll (2000) identifies learning as input driven, which means that when the learners fail to analyse the language data provided in the input, acquisition of L2 language is triggered. Although learners do not completely fail to acquire all the linguistic features of the L2 through input, some part of that input will be analysed and translated and some will be ignored. Therefore, total failure to acquire the linguistic parts of the L2 will block learning and consequently lead to the 'fossilisation' of that language (Sato\&Ballinger, 2016). Moreover, it would be possible for L2 learners' learning processes to be blocked, which will stop the process of learning an L2, the acquisition of L2 will fail and learners will rely on their L1 linguistic system instead. 
In summary, although Carroll's theory of the role of input is described as convoluted, it still involves many important purposes in SLA. (Gass, 2010). In Carroll's theory, input and intake are not considered to work as stimuli; rather, on the contrary, both are considered part of a mental and unconscious process that constructs the L2. In contrast to many theories related to the importance of input in SLA, Carroll differentiates between input and stimuli, as the latter is more important in explaining how the language is a process in the learner's mind, rather than the input, which is represented as the external environment. In fact, in Carroll's theory, previous research on input processing has not justified how a stimulus turns into intake.

\section{The role of interaction in $\mathrm{L} 2$ input}

Nevertheless, input is unquestionably necessary for language learning, and there is no approach or theory in SLA that goes against the significant role that input plays in enhancing language competence (Zhang, 2009). Indeed, input is important to learners because it feeds the innate system of that language through the conscious process of language learning, which aids the growth of that language (Rahimi, 2014). But, on the other hand, input by itself cannot facilitate SLA. As a result, learners' language competence in SLA cannot be sharpen and developed without being involved in interaction. Therefore, interaction refers to the exchanges of some language elements in which there is some indication of uncomprehend L2 utterances used and thus, in order to understand what that conversation (in a particular L2 context) is about, participants usually attempt to interpose the stream of the ongoing conversation (Gass\&Selinker, 2001; Rahimi, 2014).

Regarding the theories that link input and interaction, there are generally three views in the literature: behaviourist, mentalist and interactionist. Each of these theories gives a different emphasis in explaining SLA. In the behaviourist view, language learning is treated and accrued in environmental input; the process of language acquisition is therefore controlled from the external factors, which represented by the stimuli to which the L2 learners are exposed, plus, it grows by the reinforcement they receive in that input (Ellis, 2008).

On the contrary, the mentalist theory gives a minimal role to external factors such as input and highlights the significant role of (mental ability) which related to the learner's 'black box'. Thus, Mentalist theory claims that the learners' brains are the only tools that are especially equipped with certain abilities to facilitate language learning. Thus, with a minimal exposure to input, a learner's language competence can be triggered and acquisition can occur (Pica, 2005). The third view is represented by the interactionist theory (Swain, 2005), which emphasises that language learning can be reached both through input (external factor) and internal language processing (internal factor through the learner's mental abilities), which emphasises the role played by the contribution of the learners' inner mechanism of language learning and external environment, as both factors are involved in the interaction activities.

However, according to Krashen's theory of input, input has a significant impact on SLA (Zhang, 2009). Based on Krashen's input hypothesis, SLA can take place only when the L2 learner recognises the language input, which, consequently, consists of various L2 rules that are more advanced in level than the current language level of the learner, such as grammatical forms of L2. (Ellis \& He, 1999). Krashen suggests that the right level of input is attained automatically when interlocutors succeed in making themselves understood in communication' (Krashen, 1985, as cited in Zhang 2009, p.92). In Krashen's view, in SLA the Input Hypothesis is crucial for language learning, as L2 acquisition is contingent on comprehensible input (Zhang, 2009). For example, interaction takes place in the classroom, and the learners receive comprehensible input from the teachers, whose main role is to facilitate language learners through this input. However, when negotiation occurs in any language input, learners' production of language, which is defined as 'output', will enhanced and monitored (Pérez-Vidal, 2017). The process of linguistic information from 'input' to 'output' can only happen through interaction. According to Krashen, in this case learners selectively take in 'portions of comprehensible input and choose correct linguistic form to express themselves. This process makes it possible for the learners to internalise what they have learnt and experienced' (as cited in Zhang 2009, p.93).

In addition to Karshen's theories of input and interaction, Gass (1997) particularly stressed the importance of input acquisition and processing of L2 linguistic components through negotiated interaction. As a matter of fact, learners are pushed to negotiate for meaning in L2 input when they fail to communicate using the target language. Also, according to Sun (2008), when learners receive further and usable input, through the act of elaboration and clarification for comprehension, some specific problematic features in L2 might draw those learners' attention. As a result, through this input, learners will make a conscious comparison between their current level of language and the information they received; thus, the chances of interaction using the target language (L2) will increase. Accordingly, Gass (1997) asserts that input could be conceivably enhanced through negotiated interaction for L2 learners by three different approaches. First, if input is ensured to be more comprehensible that is essential for the development of L2. Second, in order to achieve effective L2 communication, linguistics forms that are problematic for learners should be identified and forced to be processed by learners in order to impede comprehension. The third approach claims that 'through negotiation, L2 learners receive both positive and negative feedback that are juxtaposed immediately to the problematic form, and the close proximity facilitates hypothesis-testing and revision' (Sun, 2008, p.7). In light of this, the interaction role of Gass's model and its influence on L2 acquisition should be described as a facilitator of learning, 'not a mechanism for learning' (Gass, 1997, p.242). 
However, interaction is a fundamental component of any communicative L2 environment. In fact, in any comprehensible input, such as 'language classroom', the process of information through interaction is fatal to L2 learning. Allwright (1984) refers to interaction as the 'fundamental fact of classroom pedagogy' (p.156). Thus, through interaction L2 learners are engaged in using the target language, which as a result creates comprehensible output. These kinds of learning attempts will become conscious learning sources of input for other learners. Nevertheless, through interaction, L2 learners may misunderstand some linguistic forms of the target language, which may arise frequently due to different factors, either internal or external, or on different language occasions such as contextual, syntactic, phonological, or cultural (Zhang,2009, Duff, 2019).

In fact, for L2 learners, to interact means to deliver the message using the target language, and in order to do that they may use different strategies to convey their intended meaning by interaction only and within a language input. To sum up, input and interaction are crucially related and play a critical role in the development of SLA. By all means of interaction, L2 learners develop their language competence through the comprehensible input where language acquisition takes place.

\section{Conclusion}

The current paper has aimed to present a brief review of the role and prominence of language input in SLA. Accordingly, the role of input in L2 was discussed from the perspectives of different theories in SLA input. Also, how input is processed by L2 learners and assimilated in SLA is discussed and explored in the light of four models related to language input.

The study also shed light on the most significant theories that focused on the impact of input in SLA development and acquisition. Learners and linguists require to acknowledge these L 2 theories and use them as a source of input to assist the learning process. In fact, the role of input has provided the main hypothesis for the research development in SLA. For instance, Krashen long ago $(1985,1989)$ argued that 'comprehensible input' is crucial and sufficient for effective SLA. He designated language input to be comprehended in meaning in relation to the different linguistics forms of L2 that are different from learners' current language proficiency. To this point, however, what can be concluded and summarised from Krashen's Input Hypothesis is that language input is crucial for SLA. In other words, regardless of its type, input is indisputably required for SLA. Accordingly, various types of input are debated in the literature, including modified input, internationally modified input, and modified output, comprehended input and incomprehensible input; all of these fit under the definition of the comprehensible input for SLA. In point of fact, although different studies conducted either to support Krashen's input hypothesis or criticise it, most research emphasise and highlight the significant role that comprehensible input plays in language input and SLA.

On the whole, the four theories discussed in this paper are vital to SLA, either through interaction or the cognitive abilities of L2 learners. Input works in most theories as facilitative rather than as a hindrance to language learning, although how input turns into intake is still debated, according to Caroll's theory. According to Carroll's Autonomous Induction Theory (1999, 2001, 2007, Saito\&Akiyama, 2017), the level of representation in the processing system of L2 is discussed within the scoop of different types of input such as input to learning or input to processing. However, as this goes in line with the role of input, investigation in the field is still conducted by a plethora of scholars on input and learners' knowledge, and on the significance of interaction for the development of SLA. In addition, some recent studies that focus on the cognitive abilities of individual learners of L2 have examined a variety of interpretations in SLA process (Patten \& Benati, 2010; Banati, 2005; Nekoueizadeh, 2014; Baddeley, 2003). These studies on cognitive and unconscious learning may provide additional evidence, while further investigation of the models reviewed in this research may provide more understandable views on the process of SLA.

\section{Bibliography}

Dr. Nesreen Alahmadi is an Assistant professor at Tibah University. She received her P.hD in Applied Linguistics, School of Languages, Cultures, and Societies at Leeds University, United Kingdom. Her research interests include, second language acquisition and English language teaching and learning.

\section{References:}

[1] Akan. M., The influencing factors of language development: Learners developing second and foreign languages, Bulletin of Advanced English Studies,1(1)(2018), 119-129, https://doi.org/10.31559/baes2018.1.1.10

[2] Allwright. R., The importance of interaction in classroom language learning, Applied Linguistics, 5(2)(1984),156-171, https://doi.org/10.1093/applin/5.2.156

[3] Baddeley. A., Working memory and language: An overview, Journal of Communication Disorders, 36(3)(2003), 189-208, https://doi.org/10.1016/s0021-9924(03)00019-4 
[4] Bahrani. T., Importance of language input in language learning, International Research Journal of Applied Linguistics, 6(10)(2013), 1376-1379.

[5] Benati. A., The effect of processing instruction, traditional instruction and meaning-output instruction on the acquisition of the English past simple tense, Language Teaching Research, 9(1)(2005), 67-93, https://doi.org/10.1191/13621688051r154oa

[6] Brown. H. D., Principles of language learning and teaching, Longman, (2007)

[7] Carroll. S. E., Putting 'input' in its proper place, Second Language Research, 15(4)(1999), 337-388, https://doi.org/10.1191/026765899674928444

[8] Carroll. S. E., Input and evidence: The raw material of second language acquisition, John Benjamins, (2001)

[9] Carroll. S. E., Autonomous induction theory. In B. VanPattern, \& J. Williams (Eds.), Theories in second language acquisition (pp. 155-200). Lawrence Erlbaum Associates, Inc, (2007)

[10] Doughty. C., \& Long, M. H., The handbook of second language acquisition, Blackwell, (2003)

[11] Duff. P. A., Social dimensions and processes in second language acquisition: Multilingual socialization in transnational contexts, Modern Language Journal, 103(5)(2019), 6-22, https://doi.org/10.1111/modl.12534

[12] Ellis. N. C., Essentials of a theory of language cognition, Modern Language Journal, 103(1)(2019), 39-60, https://doi.org/10.1111/modl.12532

[13] Ellis. R., The study of second language acquisition, Oxford University Press, (1994)

[14] Ellis. R., \& He. X., The roles of modified input and output in the incidental acquisition of word meanings, Studies in Second Language Acquisition, 21(2)(1999), 285-301, https://doi.org/10.1017/s0272263199002077

[15] Ellis. R., The study of second language acquisition (2nd ed.), Oxford University Press, (2008)

[16] Fang. X., The role of input and interaction in second language acquisition, Cross-Cultural Communication, 6(1)(2010), 11-17.

[17] Gass. S., Integrating research areas: A framework for second language studies, Applied Linguistics, 9(2)(1988), 198-217, https://doi.org/10.1093/applin/9.2.198

[18] Gass. S., ELT methodology from a learning perspective, Paper presented at Second Chulalonkorn University Conference on Language Teaching, Bangkok, Thailand, (1991)

[19] Gass. S., Input, interaction and second language production, Studies in Second Language Acquisition, 16(3)(1994), 283-302, https://doi.org/10.1017/s0272263100013097

[20] Gass. S., Input, interaction and the second language learner, Lawrence Erlbaum Associates, Inc, (1997)

[21] Gass. S. M., \& Selinker. L., Second language acquisition: An introductory course (2nd ed.), Lawrence ErIbaum Associates, Inc, (2001)

[22] Jackendoff. R., Foundations of language, Oxford University Press, (2002)

[23] Hulstijn. H., Is the second language acquisition discipline disintegrating?, Language Teaching, 46(4)(2013), 511-517, https://doi.org/10.1017/s0261444811000620

[24] Krashen. S., The input hypothesis: Issues and complications, Longman, (1985)

[25] Krashen. S., We acquire vocabulary and spelling by reading: Additional evidence for the input hypothesis. Modern Language Journal, 73(4)(1989), 440-464, https://doi.org/10.1111/j.1540-4781.1989.tb05325.x

[26] Krashen. S., Principles and practice in second language acquisition (1st internet edn), Oxford University Press, (2009)

[27] Liu. D., A critical review of Krashen's input hypothesis: Three major arguments, Journal of Education and Human Development, 4(4)(2015), 139-146.

[28] Long. M., Input, interaction and second language acquisition (Unpublished doctoral dissertation), University of California, Los Angeles, (1980)

[29] Long. M., Input and second language acquisition theory. In S. Gass, \& C. Madden (Eds.), Input in second language acquisition (pp. 377-393). Newbury House, (1985) 
[30] Long. M., The role of the linguistic environment in second language acquisition, In W. Ritchie, \& T. Bhatia (Eds.), Handbook of second language acquisition (pp.525-570). Academic Press, (1996)

[31] Long. M., In defense of tasks and TBLT: Nonissues and real issues, Annual Review of Applied Linguistics, 36(2016), 5-33, https://doi.org/10.1017/s0267190515000057

[32] Long. M. H., Instructed second language acquisition (ISLA): Geopolitics, methodological issues, and some major research questions, Instructed Second Language Acquisition, 1(1)(2017), 7-44, https://doi.org/10.1558/isla.33314

[33] Maftoon. P., Carroll's autonomous induction theory: Combining views from UG and information processing theories, Journal of Language Teaching and Research, 6(2)(2015), 423-428, https://doi.org/10.17507/jltr.0602.24

[34] Mackey. A., \& Gass. S. M., Second language research: Methodology and design. Routledge, (2015)

[35] McCarthy. M., A discussion of the role of input and output in second language acquisition, M.A. thesis. University College Cork, (2014)

[36] McLaughlin. B., The monitor model: Some methodological considerations, Language Learning, 28(2)(1978), 309-332, https://doi.org/10.1111/j.1467-1770.1978.tb00137.x

[37] Nekoueizadeh. M., The role of input in second language acquisition, Journal of Advances in Linguistics, 1(1)(2014),1-6.

[38] Patten. V. B., \& Benati. A. G., Key terms in second language acquisition, Continuum international publishing group, (2010)

[39] Pérez-Vidal. C. , Study abroad and ISLA. In S. Loewen, \& M. Sato (Eds.), The Routledge handbook of instructed second language acquisition(pp. 339-360). Routledge, (2017)

[40] Pica. T., Second language acquisition research and applied linguistics, Studies in Second Language Acquisition, 11(2)(2005), 63-90.

[41] Rahimi. S., On the role of input and interaction in second language acquisition, International Journal of Language Learning and Applied Linguistics World, 6(2)(2014), 136-149.

[42] Rezabeigi. M., \& Shakouri. N., On the plausibility of Carroll's autonomous induction theory in SLA. The Iranian EFL Journal, 11(3)(2015), 81-99.

[43] Shimanskaya. E., On the role of input in second language acquisition: The case of French strong pronouns, Language Learning, 68(3)(2018), 780-812, https://doi.org/10.1111/lang.12298

[44] Saito. K., \& Akiyama. Y., Video-based interaction, negotiation for comprehensibility, and second language speech learning: A longitudinal study, Language Learning, 67(1)(2017), 43-74, https://doi.org/10.1111/lang.12184

[45] Sato. M., Interaction mindsets, interactional behaviors, and L2 development: An affective-social-cognitive model, Language Learning, 67(2)(2016), 249-283, https://doi.org/10.1111/lang.12214

[46] Sato. M., \& Ballinger. S., Understanding peer interaction: An overview of the research. In M. Sato \& S. Ballinger (Eds.), Research synthesis and directions (pp. 1-30). John Benjamins, (2016)

[47] Sun. Y., Teachers College, Columbia University, Working Papers in TESOL \& Applied Linguistics, 8(1)(2008).1-10.

[48] Swain. M. The output hypothesis: Theory and research. In E. Heinkel (Ed.), Handbook of research in second language teaching and learning (pp. 471-483). Lawrence Erlbaum Associates, Inc, (2005)

[49] VanPatten. B., \& J. Williams, Input processing in adult second language acquisition. In B. VanPatten, \& J. Williams (Eds.), Theories in second language acquisition: An introduction (pp. 115-135). Lawrence ErIbaum Associates Publishers, Inc, (2007)

[50] VanPatten. B., Situation instructed language acquisition: Facts about second language acquisition. Instructed Second Language Acquisition, 1(1)(2017), 45-60.

[51] Zhang. S., The role of input, interaction and output in the development of oral fluency, English Language Teaching, 2(4)(2009), 91-100, https://doi.org/10.5539/elt.v2n4p91. 